\title{
Visualization Simulation of Local Coastal Waves Based on OpenGL
}

\author{
Lei Wang and Fengju Bu \\ ${ }^{1}$ South China Sea Information Center of State Oceanic Administration \\ ${ }^{2}$ School Information Science and Engineering, Shandong Agriculture and \\ Engineering University \\ ${ }^{1}$ wangl@scsb.gov.cn, ${ }^{2}$ bufengju@126.com
}

\begin{abstract}
In allusion to problems of higher complexity in simulation of coastal waves, a dynamic model construction method of local coastal waves is proposed. This method divides period of motion of coastal waves into four phases. The solitary wave solution of KDV EQUATION is improved and optimized based on oceanographic classical theory of ocean. The method completely demonstrates period of motion of coastal waves and their forms including breaking of waves, surge of broken waves, and rollback of waves combining with particle system method. At last visualization rendering simulation of coastal waves is realized by using OPENGL. The simulation results show that the model constructed can demonstrate basic motion features of coastal waves in small scenarios.
\end{abstract}

Keywords: coastal waves; OpenGL; breaking; model; visualization; simulation

\section{Introduction}

In the past few years, modeling and rendering of natural phenomenon is an important research area of virtual reality technology development. Coastal waves are where the hydrodynamic force factor is more complicated. Submarine terrain has direct effects on waves. When waves spread to shoal water and coastal areas, wave length and spread direction are changed continuously due to depth of water, changes of terrain and coastal form, height of waves and speed of waves. Changes are like refraction of wave direction, height of waves increase and then energy is concentrated, waveform rolls, breaking and reflection and diffraction etc. These phenomena have huge effects on both coastal projects and coastal landform. Therefore, researches of coastal waves are of great importance to national defense and shipping and so on.

Unlike waves in deep water area in ocean, coastal waves are affected by submarine landform. When entering coastal areas (depth of water is approximately $1 / 2$ of wave length), crest of wave becomes sharp and steep, through becomes flat and at the end wave length is close to infinitely large. Considering that coastal waves' motion morphology is more complicated and many factors are involved in the motion, major researches of coastal waves are: Peachey [1] conducted modeling to coastal waves by adopting height field realizing wave phasic calculation method and wave breaking modeling method under influences of submarine landform; Kass [2] simplified the offshore equation and conducted simulation of wave animation through Airy wave theory. Manual [3] realized the simulation of offshore reflection effect to waves by adopting geometric optical method; Yong Chen [4] used conical wave to build up waveform and then realized wave reflection with transformation net combined by wave direction ray and crest ray; Hagen [5] simulated water flow movement on rugged landform by means of high-resolution central upwind based on CPU hardware acceleration; Mihalef [5] generated waveform base by using Navies- 
Stokes equation and then realized simulation of offshore equation based on control of dynamic parameters.

From relative literatures, simulation of coastal waves is more complicated in comparison with simulation of other natural scenes because scene factors are more, thus the simulation is more challenging. No single general method can be used to simulate and demonstrate various features and motion forms of coastal waves. All the researches listed above were done for specific problems. One or more methods were combined to construct coastal wave model in different scenes. Methods adopted can be summarized as: 1), conduct wave analysis and propose simple physical model from hydro mechanical perspective; 2), conduct simulation from perspective of geometric shapes such as cosine functions. As to specific description and simulation of local coastal waves' motion morphology, researches are lack and further meticulous work is needed. This thesis takes motion morphology of coastal waves as research target, attempts to demonstrate motion period and motion morphology of local coastal waves by means of simulation and finally analyze simulation results.

\section{Modeling Method}

In order to demonstrate features and motion characteristics of coastal waves, this paper tried to do the following research works: based on oceanographic classical theory of ocean and solitary wave theory of KDV EQUATION, realized complete motion period simulation of local coastal waves as well as breaking of waves, surge and rollback of waves combining with optimized particle system. Motions and forms of coastal waves are affected by many complicated natural factors and have certain irregularity. This paper simplified environmental conditions of offshore motion: shore side steep hill is uniform and horizontal and tension on the surface of sea water is neglected.

\subsection{Basic Theory of Waves}

Waves refer to spread of fluctuation shapes on sea surface. Technically speaking it is not real periodical changes but sine wave or simple fluctuate overlay to a first approximation. The simple fluctuate slope surface can be described by a sine curve.

There are many kinds of oceanic waves that are caused by different factors. For example wind-stress on sea surface, volcano, earthquake and sun and moon tide generating forces deep on the seabed or besides the coast. Most waves are caused by wind blow on sea surface. Wave caused by wind is called wind wave of which size is determined by wind speed, wind duration and wind span. Waves discussed in this paper refer to fully grown up wind wave spread to off-shore. Define depth of water as $d$, wind speed in certain sea area as $U$, the wind wave calculation equation defined in Seaport Hydrology Criterion [7] is:

$$
\begin{aligned}
& g H_{1 / 3} / U^{2}=5.5 \times 10^{-3}\left(g F / U^{2}\right)^{0.35} \\
& g T_{s} / U=5.5 \times 10^{-3}\left(\mathrm{gF} / U^{2}\right)^{0.233} \\
& g F / U^{2}=1.2 \times 10^{-2}(\mathrm{gt} / U)^{1.3}
\end{aligned}
$$

For fully grown-up waves, the equation is [7]:

$$
H_{1 / 3}=2.18 \times 10^{-2} U^{2}
$$

Definitions of parameters in equations (1) to (4) are as shown in the following Table 1: 
Table 1. Definitions of Parameter 1

\begin{tabular}{|c|c|c|}
\hline No. & parameter & Definition \\
\hline 1 & $\mathrm{H}_{1 / 3}$ & $\begin{array}{c}\text { significant wave } \\
\text { heights }(\mathrm{m})\end{array}$ \\
\hline 2 & Ts & $\begin{array}{l}\text { significant wave } \\
\text { period(s) }\end{array}$ \\
\hline 3 & $\mathrm{U}$ & $\begin{array}{l}\text { significant wave } \\
\text { period(s) }\end{array}$ \\
\hline 4 & $\mathrm{~F}$ & wind $\operatorname{span}(\mathrm{m} / \mathrm{s})$ \\
\hline 5 & $\mathrm{~T}$ & wind duration(s) \\
\hline 6 & g & $\begin{array}{c}\text { gravitational } \\
\text { acceleration }\left(\mathrm{m} / \mathrm{s}^{2}\right)\end{array}$ \\
\hline
\end{tabular}

\subsection{Construction of Wave Model}

Under general circumstances, when depth of water is larger than half of wave length, spread of waves can be considered not to be influenced by seabed landform. Thus the offshore range is defined as: area where depth of water is smaller than half of wave length and at the same time smooth transition of coastal areas and deep water areas is taken into account.

Crest of coastal waves becomes sharper and steeper and trough becomes flatter due to effects of seabed landform and at the end wave length gradually gets close to infinitely large. There is only one crest but no trough. This paper attempts to divide the whole process of coastal wave motion into four phases which are wave rolls, rolling wave generates scum along with breaking occurring when it touches sea surface, surge of broken waves and rollback of waves. In consideration of wave motion morphology, this paper adopts solitary wave to conduct wave simulation. Solitary wave is a limiting case of conical wave. Its waveform is a lapse wave theory. In spread in offshore sea, waveform of solitary wave is a single crest without trough and wave length is infinitely large. Therefore, features of solitary wave waveform are similar with those of coastal wave motion morphology. The firstorder solution of wave surface equation of solitary wave is as follow [8]:

$$
\begin{aligned}
& L(f)=(\operatorname{rand}() \% 250 / 50)+1 / 2 \mathrm{~T} \\
& c=\sqrt{g(h+H)}
\end{aligned}
$$

Define a random water particle coordinate in water body $(\mathrm{x}, \mathrm{z})$, horizontal velocity component $\mathrm{u}$, vertical velocity component $\mathrm{w}$. the first-orders of $\mathrm{u}$ and ware respectively [8]:

$$
\begin{gathered}
u=\sqrt{g h} \frac{H}{h} \sec ^{2}(\mathrm{x}) \\
\mathrm{w}=\sqrt{3 g h} \frac{z}{h}\left(\frac{H}{h}\right)^{3 / 2} \sec ^{2}(\mathrm{x}) \tan (\mathrm{x}) \\
x=\sqrt{3 H / 4 h^{2}}(x-c t)
\end{gathered}
$$

To realize visualization within three-dimensional coordinate system, velocity component calculation equation in direction of depth $\mathrm{z}$ is added as:

$$
\mathrm{v}=\sqrt{g h} \frac{H}{h} \sec ^{2}(\mathrm{x})
$$


The motion direction of horizontal speed $\mathrm{u}$ is to surge up to coast with vertical speed $\mathrm{w}$ being lifting of waves. When it reaches maximum value, breaking of waves is formed.

Definitions of parameters in equations (5) to (10) are as shown in the following Table 2:

Table 2. Definitions of Parameter 2

\begin{tabular}{|c|c|c|}
\hline No. & parameter & definition \\
\hline 1 & $\mathrm{~h}$ & depth of water(m) \\
\hline 2 & $\mathrm{H}$ & height of waves(m) \\
\hline 3 & $\mathrm{c}$ & speed of waves $(\mathrm{m} / \mathrm{s})$ \\
\hline 4 & $\mathrm{u}$ & $\begin{array}{l}\text { Horizontal velocity of } \\
\text { proton }(\mathrm{m} / \mathrm{s})\end{array}$ \\
\hline 5 & $\mathrm{w}$ & Vertical velocity of proton $(\mathrm{m} / \mathrm{s})$ \\
\hline 6 & $\mathrm{v}$ & $\begin{array}{c}\text { Depth velocity component of } \\
\text { particle }(\mathrm{m} / \mathrm{s})\end{array}$ \\
\hline
\end{tabular}

\subsection{Breaking of Waves}

From the equations in the chapter above, along with decrease of depth of water, length and speed of waves also decrease but height of waves increases gradually. When depth is small enough, breaking of waves emerges.

This thesis adopts geometric wave breaking judgment method according to which condition of wave breaking is: fluidic horizontal velocity of proton at crest $\mathrm{u}>\mathrm{c}$. When horizontal speed of particle satisfies this condition, fluidic particle at crest will fly away from wave surface, forming breaking wave. It is stable to adopt geometric method as judgment condition of wave breaking and meanwhile the adopted wave theory has fewer effects on the judgment condition.

As to waves that satisfy breaking condition, particle system is used to conduct practical simulation. Particle system is technology for simulation of some certain fuzzy phenomena in three-dimensional computer graphics. Phenomena simulated by using particle system include many abstract visions like fire, explosion, smoke, water flow and spark. Concrete realization method in simulation phase is: calculate the number of new particle according to generation speed and interval. Every particle is generated in certain three-dimensional space position according to the position of ejector and the given generation zone. The parameters such as speed, color and life cycle etc. are initialized according to parameters of ejector. After that, check and make clear whether every particle has exceeded life cycle. If yes, wipe them off from the simulation process; or else simulate positions and features of changed particles. Particles in this research are control randomly in terms of generation time, number and size etc. The generation positions of particles are where the rolled wave just touches sea surface. At the same time horizontal and vertical speed randomly generated can demonstrate effectively the irregularity of particles after wave breaking.

According to motion characteristics of coastal waves and breaking index, define motion parameter of particle $m$ as:

$$
\begin{aligned}
& V_{m x}=c(1+(\operatorname{rand}() \% 100 / 100-1 / 20)) \\
& V_{m x}=c(1+(\operatorname{rand}() \% 100 / 200-1 / 40)) \\
& L(f)=(\operatorname{rand}() \% 250 / 50)+1 / 2 \mathrm{~T} \\
& L\left(f_{i}\right)=L\left(f_{i-1}\right)-1
\end{aligned}
$$


Definitions of parameters in equations (11) to (14) are as shown in the following Table 3:

Table 3. Definitions of Parameter 3

\begin{tabular}{ccc}
\hline $\begin{array}{c}\text { No } \\
\boldsymbol{1}\end{array}$ & $\begin{array}{c}\text { Parame } \\
\text { ter }\end{array}$ & definition \\
\hline $\mathbf{1}$ & $\mathrm{U}$ & $\begin{array}{c}\text { Horizontal velocity of } \\
\text { proton }(\mathrm{m} / \mathrm{s})\end{array}$ \\
$\mathbf{2}$ & $\mathrm{C}$ & $\begin{array}{c}\text { speed of waves }(\mathrm{m} / \mathrm{s}) \\
\text { Horizontal velocity of } \\
\text { particle }(\mathrm{m} / \mathrm{s})\end{array}$ \\
$\mathbf{3}$ & Vmx & $\begin{array}{c}\text { Vertical velocity of } \\
\text { particle }(\mathrm{m} / \mathrm{s})\end{array}$ \\
$\mathbf{4}$ & Vmz & motion period of waves \\
\hline
\end{tabular}

The highest moment particle can reaches is: $\mathrm{Vmz}=0$; meanwhile, define that the height of particle cannot be lower than the height of sea surface.

According to motion rules of practical particle, define horizontal acceleration of particle $\mathrm{m}$ as 0 , vertical acceleration asg. Life value of particle attenuates as motion time goes on. When L (f) is 0 , particle life cycle is over.

\subsection{Surges and Rollback of Waves}

According to motion rules of coastal waves in real scene, when breaking happens to offshore wave, spindrift and scum are generated. Breaking spindrift and wave will surge up to coast after which certain rollback distance of waves will also emerge. When all points in certain range surge up to coast with waves, waves enter into their rollback phase. However, since solitary wave is a lapse wave, water particles only move in direction of spread but never move backwards. Hence to realize surges and rollbacks of waves, the paper adds an offset to the original solitary wave model. Breaking spindrift impacts coast for a distance then rollback of waves reach position calculated by solitary wave model. Defined offset parameter is as the following equation:

$$
\text { offset }=\cos (m / 2) \lambda
$$

Definitions of relevant parameters of equation (15) are shown in Table 4:

Table 4. Definitions of Parameter 4

\begin{tabular}{ccc}
\hline No. & $\begin{array}{c}\text { parame } \\
\text { ter }\end{array}$ & definition \\
\hline $\mathbf{1}$ & offset & offset \\
$\mathbf{2}$ & c & speed of waves $(\mathrm{m} / \mathrm{s})$ \\
$\mathbf{3}$ & $\mathrm{m}$ & Offset factor, data range is \\
& & {$[-1,1]$} \\
$\mathbf{4}$ & $\mathrm{T}$ & Time $(\mathrm{s})$ \\
$\mathbf{5}$ & $\lambda$ & Length of wave $(\mathrm{m})$ \\
\hline
\end{tabular}


Define that when offset $>0$, positive deviation of waves happens, which is surges of waves;

When offset $<0$, negative deviation of waves happens, which means rollback of waves motion happens to waves.

The offset is a dynamic changing process, analysis as follow:

When $m=1$, offset $=0$, no deviation happens to waves, same as the previous model;

When $\mathrm{m}=0$, offset $=\lambda$, waves deviate forwards for a distance of one wave length;

When $\mathrm{m}=-1$, offset $=-\lambda$, waves deviate backwards for a distance of one wave length;

When value is in the middle range, it refers to the dynamic distance of surge and rollback of waves.

To ensure the visual continuity, it is defined that the beginning of rollback of waves is the rolling moment of another wave.

\section{Simulation Results}

Software environment of model simulation adopts $\mathrm{VC}++6.0$ and OpenGL graphics base development is used, frame rate is $30 \mathrm{fps}$, operating system is: windows 7 Server pack 1. Hardware environment is as shown in Table 5 below:

Table 5. Simulation Hardware Environment Description

\begin{tabular}{ccc}
\hline No. & Name & Description \\
\hline 1 & CPU & AMD Athlon(tm)64×2 \\
& & $2.30 \mathrm{HZ}$ \\
2 & RAM & $4.0 \mathrm{~GB}$ \\
3 & VGA & NVIDIA GeForce 210 \\
& Card & \\
\hline
\end{tabular}

Scene 1: according to the fluctuate non-convergence effect in KDV EQUATION, in the spreading process of solitary wave, under certain effects of wind force, waves have different forward velocity at different heights and the closer they are from shore side, the higher is the wave. Waves will become more forward gradually under functions of shore-side resistance force (lower part of waves is more affected while higher part less). Then wave rolling occurs with breaking wave being generated. The computer simulation effect of this process is as demonstrated in Figurer 1 below.

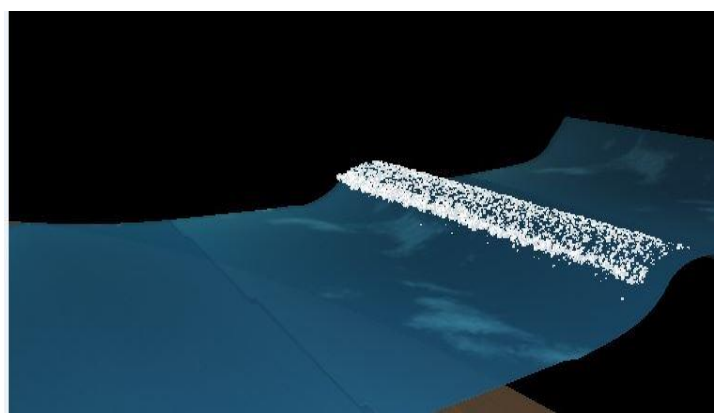

Figure 1. Generation of Breaking Waves

Scene 2: breaking waves surge up for a certain distance and then rollback of waves occurs, simulation results are as follow being demonstrated in Figurer 2: 


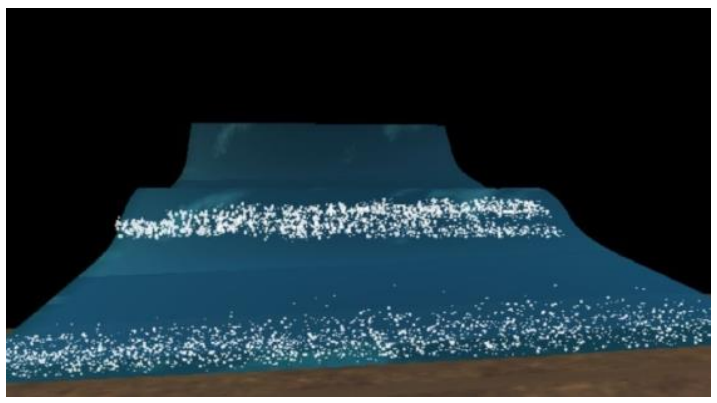

\section{Figure 2. Waves Surge of Broken Waves and Rollback of Waves}

Scene 3: rollback of broken waves and the rolling generation of next wave (the beginning of rollback of waves is simultaneously the rolling-up moment of another wave), simulation results are as demonstrated in Figurer 3:

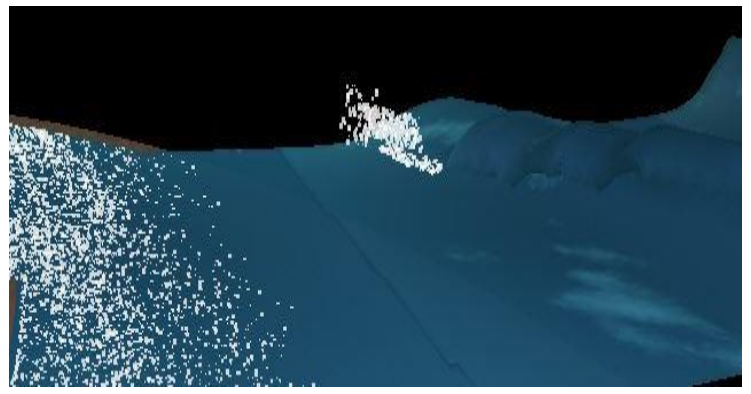

Figure 3. Rollback of Waves of Broken Waves and Next Plunging Breaker Generation Moment

\section{Conclusion}

This paper constructed motion period model of coastal waves combing with particle system on the basis of oceanographic classical theory of ocean and solitary wave solution theory based on KDV EQUATION. The research realized simulation of motion morphology of local coastal waves under certain conditions. The simulation results showed that this model to some degree restored the motion rules and scenes of coastal waves and further divided innovatively the run cycle of coastal waves. It is a new idea to realize coastal wave simulation.

In comprehensive analysis of simulation results, the improved model conducted innovatively simulation realization to the basic motion cycle and features of coastal waves. It can clearly demonstrate the basic form and appearance characteristics of coastal wave motion. However, the model has certain limitations. Existing problems and working direction of next step are as follow:

(1) The existing model has problems of model rendering accuracy and rendering efficiency so far. The next step should consider using CPU hardware acceleration technology, combining improved particle system, to realize wave simulation in big scenes and to solve the contradiction of model accuracy and efficiency.

(2) The elaborating degree of model is not enough; the next step should consider using texture mapping technology to carry out more elaborated simulation of coastal waves.

(3) Based on research of this paper, construct a more enriched offshore scenario simulation, creating motions like crash of waves and rocks on sea surface, wave breaking and splash etc. 


\section{References}

[1] Peachey D. R., "Modeling Waves and Surf”, Computer and Graphics, vol. 20, no. 4, (1986), pp. 65-74.

[2] Kass R. and Rapid M. G., "Stable Fluid Dynamics for Computer Graphics", Computer Graphics, vol. 24, no. 4, (1990), pp. 49-57.

[3] Manuel N. G. and Kenton F., "An Accurate Model of Wave Refraction over Shallow Water", Computers Graphics, vol. 26, no. 2, (2002), pp. 291-307.

[4] C. Yong, C. Ge and Z. S. Jun, "Real-time Simulation of Near shore Wave", Journal of System Simulation, vol. 20, no. 3, (2008), pp. 741-745.

[5] Hagen T. R., Hjelmeryik J. M., Lie K. A. and Natvig J. R., "Visual Simulation of Shallow-Water Waves", Simulation Modeling Practice and Theory, vol. 13, no. 3, (2005), pp. 33-39.

[6] Mihalef V., Metaxas D. and Sussman M., "Dynamics and Modeling of Ocean Waves", London: Cambridge University Press, (1996).

[7] No.1 engineering survey and design institute of ministry of communications, Seaport Hydrology Criterion (JTJ213-98) MJ. Beijin: China communication press, [51140171], (2000).

[8] C. Jun, "Simulation of Offshore Waves", Wuhan: Wuhan University Press, vol. 12, (2011).

\section{Authors}

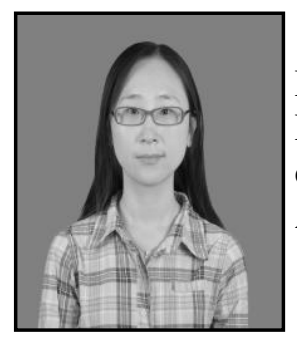

Lei Wang, she received her B. E. in Computer science (2006) and M.E in Computer Application Technology (2009) from University. Now she is an Engineer in the ocean information department. Her current interests include different aspects of Virtual reality and Artificial intelligence.

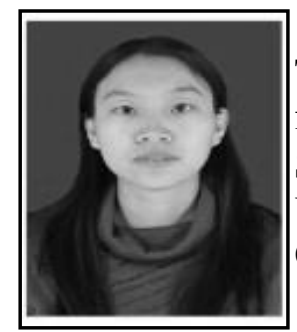

Fengju Bu, she received her B.S. in Major of Computer Science \& Technology (2006) and MSF- Master of Science in Finance (2010) from University. Now she is working at school of Information Science and Engineering, Shandong Agriculture and Engineering University. Her current interests include different aspects of Computer Applications Technology and M2M. 